\title{
EDUCATIONAL
}

TECHNOLOGY

\section{Distance education - education's new frontier}

\author{
Alex Millar \\ Department of Educational Technology \\ Victoria College, Toorak Campus
}

\begin{abstract}
"Distance education may be seen as one of those innovations which was forged on the frontier of European expansion, ... the history of distance education is to a considerable extent an example of the process by which ideas and techniques developed on the periphery have gradually been accepted and absorbed into the old heartland of European culture. Beyond that, there will be a further chapter unfolding as non-European societies observing this process adapt and modify it to their own needs." (1) Bolton (1985).
\end{abstract}

Between August 13th and 20th, 1985, more than 600 delegates from 52 countries gathered at La Trobe University in Melbourne for the Thirteenth World Conference of the International Council for Distance Education. The significance of the conference lay not so much in its statistics - though they were noteworthy - nor with the fact that this was the first conference of this organisation in Australia. Rather there was clear evidence of a growing interest in distance education in many countries and in many fields, including a surprising number outside the formal education system. The conference's significance lay also in the fact that a trend, first evident about five years ago, appeared to be showing distinct signs of firming up. This emerging trend is the convergence and overlap between distance education and a number of other fields and facets of education, namely:

1. Traditional mainstream on campus learning,

2. Telecommunications and technology,

3. Educational technology / instructional design,

4. A focus on the needs of the individual learner.

In his Broady Lecture on the second day of the ICDE conference, Prof. Geoffrey Bolton, a historian from Murdoch University, encapsulated the main elements of the convergence of distance and on-campus learning by means of the famous Turner 'Frontier Theory' of American History. In the extract at the beginning of this article, it can be seen how he used this analogy to foreshadow the accepting and absorbing of distance education ('the frontier') into traditional mainstream on-campus education ('the old heartland of European culture'). It proved to be a most pertinent analogy. Repeatedly through the conference, papers and speakers were to home in 
on this theme which appeared to dominate most other issues. It is worthwhile to note some of these references.

Prof. Bolton was in fact not the first to touch on the issue. In the opening ceremony an unexpected and intriguing allusion was made by Prof. J. A. Salmond (Acting Vice Chancellor, La Trobe University) in his welcoming remarks to delegates. Prof. Salmond told of an occasion during his childhood in New Zealand when epidemic forced the closure of all schools in the country. This did not mean, however, that the process of education in New Zealand stopped. Almost overnight, the Education Department's Correspondence School swung into action to continue the education of the nation's children. ICDE delegates could hardly have asked for a more appropriate speech of welcome.

Prof. Fred Jevons (Vice Chancellor, Deakin University) in a session on 'Organisational Structures: The Dual Mode Institution' acknowledged that 'although we owe great advances in distance education (DE) to single mode institutions, there are also some advantages in the dual mode arrangements: (2)

1. Integration of $\mathrm{DE}$ with the other teaching and administrative activities of the institution.

2. Spillover effects from DE which may raise the quality of the teaching activities.

3. Credibility. It is easier to argue for parity of esteem between two modes.

4. Economies of scale when materials prepared for DE students are also used by on-campus students.

5. Reluctance of governments to start new institutions.

6. Teaching is enriched by being conducted in association with research.

7. New Technologies lead to convergence of DE and on campus education'.

Another significant comment on the convergence theory came from Prof. Lewis Elton (University of Surrey). Prof. Elton is a notable authority and practitioner in tertiary education staff development. He acknowledged that originally he had had no real links with distance education. However, the more he worked in staff development the more he found himself borrowing from $\mathrm{DE}$ and in fact delving into the field. In acknowledging the convergence, he urged that methodology research should focus on traditional as well as distance learning modes. A pre-occupation with distance education research carried with it the implicit view that DE was not only the 'new boy', but perhaps the one that needed to prove itself. The reality, he argued, was that whatever the reasons for traditional on campus mode being regarded as the norm in tertiary education, empirical validation was not the major one.

It was interesting to see two of the 'elder statesmen' of DE, Prof. Borje Holmberg (Fern University, West Germany) and Lord Perry (Chancellor of the UK Open University) also recognising and applauding the convergence theory. Each however, had a reservation. Holmberg pointed 
out that there were many people who didn't wish to learn in a social setting, 'Therefore who are we to say that they must?' (3)

Lord Perry argued that as knowledge expands and as technological change increases, there is a greater 'need to keep people at work to continue learning'. (4) Distance mode learning is clearly the answer to this problem. However, when asked whether he would prefer to see his own children educated by the DE mode, his answer was an unequivocal 'no', on the grounds that children need to learn in a social context.

The reservations of these two eminent distance educators bring out an important rider to the convergence theory. Time and again during the conference, the question arose as to when the intersection and final integration of distance and on campus learning was likely to take place. Estimates of from 20 to 50 years were offered, but the Perry/Holmberg reservations serve to indicate that it is unwise to assume that convergence will inevitably result in a fusing of the two modes. The important questions appear to be, to what extent and how quickly will conventional on campus learning assume the desirable features of DE?

While it may be difficult to forecast a time scale for this process, what is easier is to identify the variables which will affect the timing question. Such variables will probably include the following:

1. Technological change, which, as Lord Perry observed, is increasing the need for vocational and professional in-service education and training. It is also producing exciting technological developments that will facilitate access to information, data and resources for both off and on campus students.

2. The way in which DE responds to the issue of software versus what Liz Burge (OISE, Canada) described as 'warmware' - people or teaching staff! Total reliance on software will slow down convergence, mainly because software development is a time-consuming and costly process. Blending 'warmware' through teleconferencing for example would appear to be an optimal approach educationally and financially. (5)

3. The attitude of government on the matter: largely for financial reasons, government guidelines for tertiary "education from bodies such as the Commonwealth Tertiary Education Commission and the Victorian Post Secondary Education Commission have been encouraging the use of technology and distance mode learning in tertiary education.

Consistent with this approach has been the thrust of the report of a recent Federal government sponsored trade and education mission to Asia. One of the report's main recommendations was: 'That private companies, public sector bodies and tertiary education institutions should be encouraged to market overseas educational courses and services.' (6)

4. An increasing flexibility by tertiary educational administrators towards the delivery of education: interesting evidence of a more positive attitude here may be seen in the success of the Australian Film and Television School's National Graduate Diploma Scheme, and the 
agreement by five education universities in Australia, to permit the cross-crediting of courses from other institutions within the agreement. (7)

5. The attitude of students towards mixed and distance mode education versus on campus mode learning: increasingly, institutions such as the Victorian TAFE Off Campus Networks and the Victoria College (9) are finding students welcoming the opportunity to undertake at least some of their studies in the mixed and off campus modes.

6. The attitude of teaching staff towards mixed mode and distance mode learning: this could well be the factor which retards the convergence process most. What is involved here is the teaching style and attitudes of tertiary academics towards student learning. For centuries the academic has conformed to the 'font of all knowledge' syndrome and operated almost totally within the confines of the lecture theatre and tutorial room. Distance learning breaks with that tradition and in doing so poses a challenge, if not a threat, to some academics. Firstly because of the geographical factor (students are not in the classroom, but 'out there'), but more significantly because distance education rests largely on the concept of resource based learning, and a concomitant focus on students as individuals.

While the diversity of these variables make any estimate of the timing of the convergence difficult, an analysis of the variables themselves does tend to indicate that the convergence is in train and is unlikely to be reversed as a trend.

It would be too simplistic to discuss the so-called convergence theory solely in terms of traditional on campus and distance learning. Other lesser but also significant forces appear to be heading in the same direction as the main two.

\section{Briefly these are:}

1. Telecommunications and technology, may be seen as a factor contributing to the need for distance education at the in-service level, and also as the means for sophisticated distance learning delivery systems. It is worth noting here that in officially opening the ICDE Conference, Senator Susan Ryan, the Commonwealth Minister for Education, made two announcements of importance to distance education, each of which was in itself, an example of technological development. Firstly, Senator Ryan announced an 'educational window' that will be available in the Western Australian 'footprint' of AUSSAT. This arrangement will eventually apply in other states thus providing an educational broadcasting capability throughout Australia. Senator Ryan also used the ICDE forum to launch Edutel, an educational videotex gateway and data base operated by the Australian Caption Centre with government support.

2. Educational Technology and Instructional Design, which as the number of ICDE papers and sessions indicated, are being looked to more seriously by distance than on campus educators, for providing the techniques and skills necessary for the designing, developing and 
evaluating of distance materials and methods. Evidence of this particular convergence may be seen in the ICDE Conference theme 'Flexible Designs for Learning'. Furthermore, approximately 45 per cent of the conference papers were on topics that were directly related to the Educational Technology / lnstructional Design fields.

3. The third of the lesser convergents is the focus on the needs of the individual learner. We can see here a trend also increasingly evident in on-campus education and which has been fuelled over the last decade or so by the work of Bruner, Rogers and Knowles.' (10)

Malcolm Knowles is a comparative newcomer to the educational scene, but has been exerting strong influence in the industrial training because of his focus on androgogy, the study of adult learning. For Knowles, the difference between pedagogy and androgogy is that the adult's learning should be self-directed. Interesting evidence of the influence of these three in distance education may be seen in a comparison by Nigel Paine (Scottish Council for Educational Technology). (11) He observed that in the previous ICDE Conference in Vancouver, the focus was on the institution and the systems of distance education, whereas in Melbourne the focus was on the student and his/her individual needs.

It is also interesting to note that in Australia's only Graduate Diploma in Distance Education (South Australian College of Advanced Education), the course team has been critical of 'the pre-eminence given to course materials or learning packages over individual students'. (12) At their conference session they went on to criticise the instructional design model for distance education:

Distance education has not been seen as the individualisation of learning but the industrialisation of teaching; product has been elevated over process; didacticism stands in place of interactive learning, and the prespecification of learning experiences has triumphed over learning in which students draw on and reflect on their existing experiences.' (13)

These criticisms are most telling where adult learners are concerned. While their emphasis on individualisation is a refreshing trend, it is important that it co-exist with instructional design rather than replace it because distance education will always require a certain amount of prepared instructional materials.

Having analysed the various strands in the so-called convergence theory it remains but to examine the implications, if any, for educational technology. Whether one attends a distance education gathering such as the Melbourne ICDE Conference, or whether one peruses the current literature of distance education, one cannot help but form the view that there is an important place for educational technology in distance education. Trained educational technology specialists are able to offer materials, design and evaluation skills, experience as change agents and an understanding of and familiarity with the old and the new technologies. 
Indeed one is inclined to conclude that the full potential of educational technology, having not been fully realised in traditional education, is likely to be fulfilled in a new frontier, that of distance education.

It is fitting and indeed encouraging to conclude with another quote from Geoffrey Bolton's Broady Lecture. While Bolton is referring to distance education, there is an uncanny relevance for educational technology. Bolton's reference to Professor Geoffrey Blainey's book, The Tyranny of Distance, and of Blainey's observation in 1982 that

sometimes I think people take the phrase further than it should be taken and certainly than the book intended. My book is essentially about people and commodities, and for then the cost of distance has usually been cheap. In the history of this land, ideas have usually leaped with relative ease across the ocean and even across the inland. (14)

'If, as I believe', Bolton continues, 'Blainey is right, distance education may be seen as one of the great facilitators enabling ideas to leap across long distances. Here again the experience of new societies has resulted in useful feedback for the rest of the World.'

\section{References}

1. Prof. G. Bolton, Murdoch University, WA, Broady Lecture ICDE Conference, August 15th, 1985, Melbourne, p11.

2. Prof. F. Jevons, Vice Chancellor, Deakin University. From the abstract for session 'Organisational Structures: Dual Mode Institutions'.

3. Prof. B. Holmberg, Fern University, West Germany. 1CDE Conference Plenary Session, August 20th, 1985

4. Liz Burge, Ontario University, UK ICDE Conference Plenary Session, August 20th, 1985.

5. The Age, p3 Tuesday September 3rd, 1985.

6. Pritchard, A. L. and Jones, D. R. An evaluation study of cross crediting arrangement between Distance Education Institutions (CTEC Feb. 1985).

7. Foks, Jack (Victorian TAFE Off-Campus Network) in answer to a question in ICDE session 'Organisational Structures: Dual Mode Institutions' indicated that in his experience students were indicating a strong desire to have access to offcampus mode learning.

8. Experience at Victoria College (Toorak Campus) with students of the Graduate Diploma of Educational Technology Course.

9. See Knowles, M. S. The Adult Learner: A Neglected Species. (Houston, Gulf, 1973).

10. Paine, N. (Scottish Council for Educational Technology) ICDE Conference Plenary Session, August 20th, 1985.

11. Forster, A., King, B. and Luke, R. (SACAE) in session 'Professional Development for Distance Education, Tuesday August 20th, 1985 p3.

12. ibid.

13. Prof. G. Bolton (Murdoch University, WA) Broady Lecture ICDE Conference, August 15th, 1985, Melbourne, p12.

Please cite as: Millar, A. (1985). Distance education - education's new frontier. Australian Journal of Educational Technology, 1(2), 8-13. http: / / www.ascilite.org.au / ajet/ajet1/ millar.html 